\title{
RANCANG BANGUN TURBIN ANGIN POROS HORIZONTAL 9 SUDU FLAT DENGAN VARIASI RASIO LEBAR SUDU TOP DAN BOTTOM UNTUK MENINGKATKAN KINERJA PLTB
}

\author{
Dr. Yusuf Dewantoro H, S. T, M. T. , Ph. D. ${ }^{1}$ Wahyono S.T.,M.T. ${ }_{-2}^{2}$ \\ Ahmad Ilham Khatami ${ }^{3}$, Ardy Bagus Septian Pratama ${ }^{4}$, Dimas Hanif Arrahman ${ }^{5}$, Juniar Irmansyah ${ }^{6}$ \\ ${ }^{12)}$ Dosen ${ }^{3456)}$ Mahasiswa Program Studi Teknik Konversi Energi Politeknik Negeri Semarang Jalan Prof. \\ H. Soedarto, S.H. Tembalang, Semarang \\ Email : masyusufdh@yahoo.com
}

\begin{abstract}
Abstrak
Penggunaan energi listrik di Indonesia saat ini sangatlah tinggi, namun energi yang digunakan masih didominasi oleh energi fosil, padahal potensi energi alternatif di Indonesia sangat banyak dan belum bisa dimanfaatkan dengan baik, salah satunya adalah energi angin. Oleh sebab itu, penulis mengambil judul tugas akhir dengan tema turbin angin. Tujuan tugas akhir dari Rancang Bangun Turbin Angin Poros Horizontal 9 Sudu Flat dengan Variasi Rasio Lebar Sudu Top dan Bottom Untuk Meningkatkan Kinerja PLTB tersebut adalah untuk membuat turbin angin sumbu horizontal 9 sudu flat dengan variasi sudut sudu, menguji secara eksperimental kinerja turbin angin sudu 9 flat dengan berbagai macam variasi sudut sudu dan kecepatan angin, mengkaji karaketristik kerja turbin sumbu horizontal sudu 9 flat dengan sudut sudu dan lebar sudu top dan bottom.Pengujian dilakukan dengan menvariasikan rasio lebar sudu 1:1; 4:5; 3:5; 2:5; $1: 5$ yang semuanya di variasikan sudut sudunya dari $15^{\circ}-45^{\circ}$ dan kecepatan angin bebas sebesar $5 \mathrm{~m} / \mathrm{s}, 7 \mathrm{~m} / \mathrm{s}, 9 \mathrm{~m} / \mathrm{s}$ yang pengujiannya diawali pada beban kosong, dihasilkan putaran paling tinggi untuk semua turbin angin dengan variasi rasio lebar sudu top dan bottom. Langkah berikutnya menambah beban dengan cara menyalakan beban lampu DC yang mengakibatkan putaran turun dan daya generator meningkat hingga mencapai kapasitas maksimum turbin angin. Berdasarkan uji kinerja turbin angin, pada sudu turbin dengan rasio lebar sudu 4:5 dan sudut sudu $30^{\circ}$ dengan kecepatan angin bebas $5 \mathrm{~m} / \mathrm{s}$ memiliki nilai $\eta_{s}$ yang lebih tinggi yaitu 9,665631\% dibandingkan dengan sudu turbin dengan rasio lebar sudu lainnya, kemudian pada sudu turbin dengan rasio lebar sudu 3:5 dan sudut sudu $23^{\circ}$ dengan kecepatan angin bebas $7 \mathrm{~m} / \mathrm{s}$ memiliki nilai $\eta_{s}$ yang lebih tinggi yaitu 7,421294\% dibandingkan dengan sudu turbin dengan rasio lebar sudu lainnya, sedangkan pada sudu turbin dengan rasio lebar sudu 2:5 dan sudut sudu $18^{\circ}$ dengan kecepatan angin bebas $9 \mathrm{~m} / \mathrm{s}$ memiliki nilai $\eta_{s}$ yang lebih tinggi yaitu 5,8035\% dibandingkan dengan sudu turbin dengan rasio lebar sudu lainnya.
\end{abstract}

Kata Kunci: "Turbin angin poros horizontal", "Rasio lebar sudu top dan bottom", "Efisiensi sistem", "Tip Speed Ratio"

\section{Pendahuluan}

\subsection{Perumusan Masalah}

Energi angin merupakan salah satu potensi energi terbarukan yang dapat memberikan kontribusi signifikan terhadap kebutuhan energi listrik domestik, khususnya wilayah terpencil.
Pembangkit energi angin yang biasa disebut Pembangkit Listrik Tenaga Bayu (PLTB) ini bebas polusi dan sumber energinya yaitu angin yang tersedia di mana pun karena khususnya di Indonesia memiliki garis pantai yang sangat panjang, maka pembangkit ini 
dapat menjawab masalah lingkungan hidup dan ketersediaan sumber energi. (Saiful, 2014)

Turbin angin sumbu horizontal merupakan salah satu tipe turbin angin. Turbin angin sumbu horizontal dengan letak poros searah aliran angin yang ditangkap oleh sudu. Terdapat berbagai macam tipe turbin angin sumbu horizontal. Tipe turbin angin sumbu horizontal digolongkan berdasarkan jumlah sudunya. Umumnya bahan yang digunakan untuk membuat sudu-sudu turbin angin adalah fiber National Advistory Committee For Aeronautics (NACA) dan plat galvanis (tipe flat).

Kecepatan angin Indonesia sangat bervariasi. Pada kecepatan angin rendah menggunakan turbin angin sudu flat dengan banyak sudu (diatas delapan sudu). Kelemahan turbin ini memiliki kinerja yang rendah untuk kecepatan tinggi. Untuk potensi angin yang tinggi cocok menggunakan sudu airfoil NACA. Kelemahan turbin ini tidak dapat berputar pada kecepatan angin yang rendah.

Banyak penelitian serta pengembangan yang dilakukan pada desain Turbin Angin Sumbu Horizontal (TASH). Pengembangan banyak dilakukan pada jumlah sudu, bentuk sudu, serta bahan untuk membuat sudu. Namun belum ada penelitian mengenai TASH yang bertumpuk (berlapis). Konsep sudu bertumpuk umumnya dapat ditemui pada turbin gas maupun turbin uap. Turbin gas dibuat bertingkat (berlapis) untuk memaksimalkan potensi uap atau gas yang dialirkan ke turbin. dengan sudu turbin yang dibuat banyak tingkat dapat meningkatkan efisiensi sistem $\left(\eta_{\mathrm{s}}\right)$.
Oleh karena itu penulis tertarik mencoba membuat turbin angin sumbu horizontal yang dapat berputar pada kecepatan angin yang berbeda yaitu tipe flat 9 sudu dimana dibuat variasi rasio lebar sudu top dan bottomnya.

Diharapkan potensi angin dapat semaksimal mungkin ditangkap oleh sudu - sudu turbin angin yang dapat diputar dengan sudut tertentu yang disebut sudut sudu dan pengaturan jarak antar lapis sudu. Melalui suatu percobaan serta analisa, sehingga output yang diharapkan adalah nilai efisiensi sistemnya $\left(\eta_{\mathrm{s}}\right)$. Serta karakteristik turbin angin sumbu horizontal sudu flat bervariasi rasio lebar sudu top dan bottomnya.

\subsection{Tujuan Pembuatan}

\section{A. Tujuan Akademis}

Tujuan akademis dari pembuatan Tugas Akhir ini yang berjudul "Rancang Bangun Turbin Angin Poros Horizontal Rancang Bangun Turbin Angin Poros Horizontal 9 Sudu Flat Dengan Variasi Rasio Lebar Sudu Top dan Bottom Untuk Meningkatkan Kinerja PLTB” yaitu:

1. Memenuhi persyaratan dalam rangka menyelesaikan studi Diploma III Jurusan Teknik Mesin Program Studi Teknik Konversi Energi Politeknik Negeri Semarang.

2. Mengembangkan \& mengaplikasikan ilmu yang telah didapat selama menjalani kuliah di Program Studi Teknik Konversi Energi.

\section{B. Tujuan Teknis}

Tujuan teknis dari pembuatan tugas akhir yang berjudul "Rancang Bangun Turbin Angin Poros Horizontal Rancang Bangun Turbin Angin Poros 
Horizontal 9 Sudu Flat Dengan Variasi Rasio Lebar Sudu Top dan Bottom Untuk Meningkatkan Kinerja PLTB" yaitu:

1. Membuat turbin angin sumbu horizontal 9 sudu flat dengan variasi sudut sudu.

2. Menguji dan mengkaji kinerja turbin angin sumbu horizontal 9 sudu flat dengan variasi rasio lebar sudu top dan bottom.

\subsection{Pembatasan Masalah}

Penulis memberikan batasan batasan masalah dalam penulian tugas akhir ini yang nantinya agar tidak menimbulkan melebarnya topik bahasan yang akan menyimpang dari judul tugas akhir ini.

Adapun batasan permasalahan yang penulis berikan adalah sebagai berikut:

1. Penulis hanya merancang bangun bagian sudu turbin.

2. Penulis hanya membahas tentang turbin angin sumbu horizontal 9 sudu flat dengan variasi sudut sudu.

3. Penulis hanya membahas tentang turbin angin sumbu horizontal 9 sudu flat dengan kecepatan angin yang berbeda.

4. Penulis hanya membahas karakteristik turbin angin sumbu horizontal 9 sudu flat dan variasi rasio lebar sudu top dan bottomnya serta mendapatkan nilai efisiensi sistem $\left(\eta_{\mathrm{s}}\right)$ turbin angin.

\section{Landasan Teori}

\subsection{Daya Kinetik Turbin Angin}

Energi kinetik yang terkandung dalam angin yang ditangkap oleh turbin angin untuk memutar rotor, dengan menganggap suatu penampang melintang A, dimana udara dengan kecepatan mengalami pemindahan volume untuk setiap satuan waktu, yang disebut dengan aliran volume $\mathrm{V}$ sebagai persamaan :

$\mathrm{V}=v \times \mathrm{A}$

Keterangan :

$\mathrm{V}=$ Laju Volume Udara $\left(\mathrm{m}^{3} / \mathrm{s}\right)$

$v=$ Kecepatan angin $(\mathrm{m} / \mathrm{s})$

$\mathrm{A}=$ Luas area sapuan rotor $\left(\mathrm{m}^{2}\right)$

Sedangkan aliran massa dengan

kerapatan udara $\rho$ sebagai berikut :

$\dot{\mathrm{m}}=\rho \times v \times \mathrm{A} \ldots \ldots 2.2)$

Keterangan :

$\dot{\mathrm{m}}=$ Massa udara yang bergerak $(\mathrm{kg} / \mathrm{s})$

$\rho=$ Massa jenis udara $\left(\mathrm{kg} / \mathrm{m}^{3}\right)$

$v=\operatorname{Kecepatan}$ angin $(\mathrm{m} / \mathrm{s})$

$\mathrm{A}=$ Luas area sapuan rotor $\left(\mathrm{m}^{2}\right)$

Persamaan - persamaan di atas menunjukkan energi kinetik dan aliran massa yang melewati suatu penampang melintang A sebagai energi Pkinetik yang ditunjukkan dengan persamaan di bawah ini :

Pkin $=\frac{1}{2} \times \rho \times \mathrm{A} \times v^{3} \ldots 2.3$ )

Keterangan :

Pkin $=$ Daya kinetic angin (Watt)

$\rho \quad=$ Massa jenis udara $\left(\mathrm{kg} / \mathrm{m}^{3}\right)$

A $=$ Area penangkapan angin $\left(\mathrm{m}^{2}\right)$

$v \quad=$ Kecepatan angin $(\mathrm{m} / \mathrm{s})$

\subsection{Daya Listrik Turbin Angin}

Daya generator dapat dihasilkan dari putaran poros turbin yang berputar akibat angin yang menumbuk sudusudu, sehingga generator menghasilkan listrik dari nilai tegangan dan arus yang keluar dari generator itu sendiri, karena arus yang digunakan adalah arus DC 
maka daya listrik diperoleh melalui persaman sebagai berikut :

$\left.\mathrm{P}_{\mathrm{g}}=\mathrm{V} \times \mathrm{I} \ldots \ldots 2.4\right)$

Keterangan :

$\mathrm{P}_{\mathrm{g}}=$ Daya generator DC (Watt)

$\mathrm{V}=$ Tegangan $(\mathrm{V})$

$\mathrm{I}=\operatorname{Arus}(\mathrm{A})$

\subsection{Efisiensi Sistem Turbin Angin}

Efisiensi sistem $\left(\eta_{\mathrm{s}}\right)$ turbin angin merupakan perbandingan daya listrik yang dihasilkan dengan daya masukan berupa daya kinetik yang berasal dari kecepatan angin. Berdasarkan persamaan 2.4 dan 2.5 maka akan didapatkan kinerja sistem turbin (efisiensi sistem turbin) sebagai berikut

$\left.\eta_{\mathrm{s}}=\frac{P g}{P \text { kin }} \times 100 \% \ldots \ldots 2.5\right)$

Keterangan :

$\eta_{\mathrm{s}} \quad=$ Efisisensi sistem $(\%)$

$\mathrm{Pg}$ = Daya keluaran generator (Watt) Pkin = Daya kinetik angin (Watt)

\subsection{Tip Speed Ratio (TSR)}

Hal pertama yang diperhatikan dalam mendesain turbin angin adalah TSR (Tip Speed Ratio) atau perbandingan kecepatan di tip (ujung) turbin angin dan kecepatan angin yang didapat oleh turbin angin. TSR dapat dihitung melalui persamaan :

$$
\lambda=\frac{\Pi D n}{60 v}
$$

Keterangan :

$n=$ Kecepatan putaran poros (rpm)

$\lambda=$ Tip speed ratio

$v=$ Kecepatan angin $(\mathrm{m} / \mathrm{s})$

$\mathrm{D}=$ Diameter rotor $(\mathrm{m})$

\subsection{Hasil Rancangan}
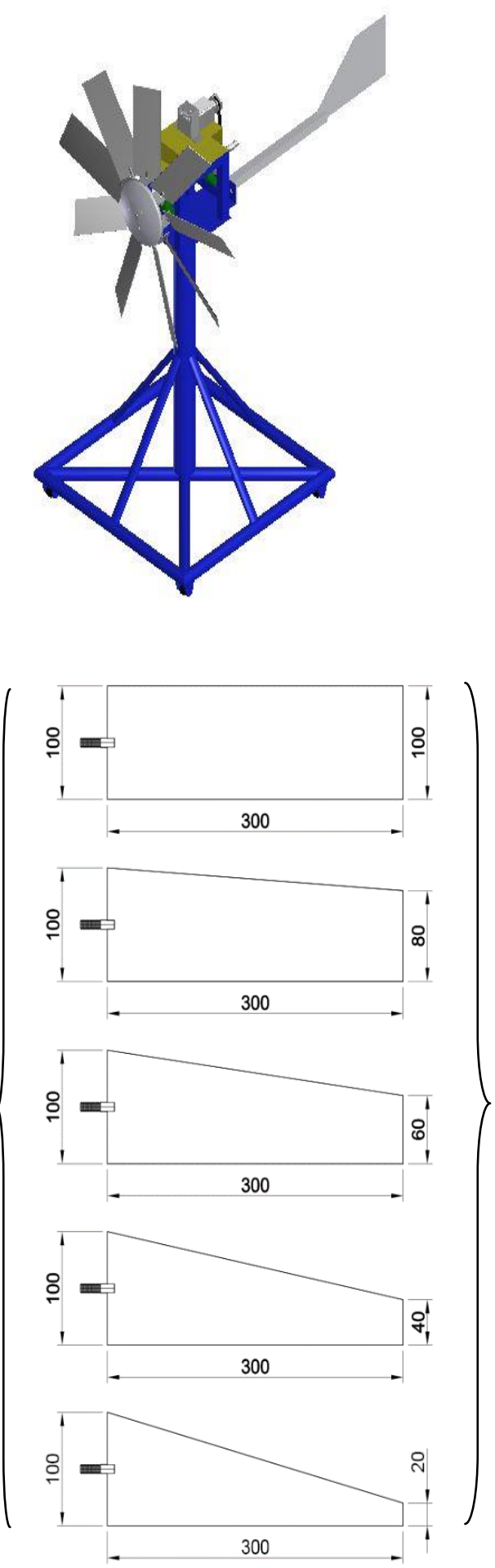


\section{Analisa Data}

4.1 Karateristik $\eta_{\mathrm{s}}$ Terbaik Terhadap TSR Turbin Angin Poros Horizontal 9 sudu Flat di Semua Variasi Rasio Lebar Sudu Top dan Bottom pada Kecepatan Angin Bebas $5 \mathrm{~m} / \mathrm{s}$

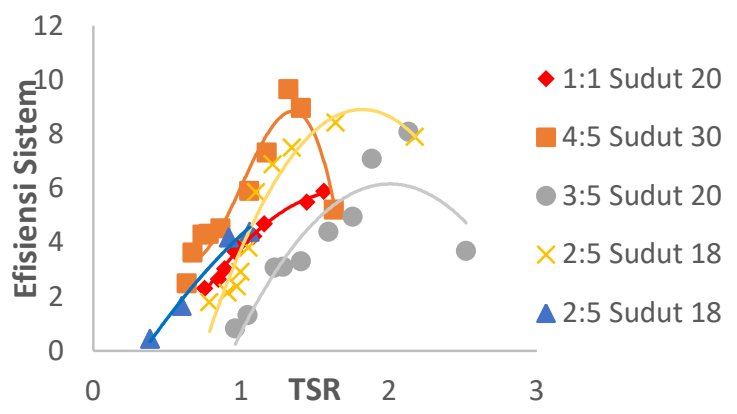

Grafik karakteristik hubungan antara efisiensi sistem $\left(\eta_{\mathrm{s}}\right)$ terbaik terhadap Tip Speed Ratio (TSR) di semua rasio lebar sudu Top dan Bottom pada kecepatan angin bebas $5 \mathrm{~m} / \mathrm{s}$

4.2 Karateristik $\eta_{\mathrm{s}}$ Terbaik Terhadap TSR Turbin Angin Poros Horizontal 9 sudu Flat di Semua Variasi Rasio Lebar Sudu Top dan Bottom pada Kecepatan Angin Bebas $7 \mathrm{~m} / \mathrm{s}$

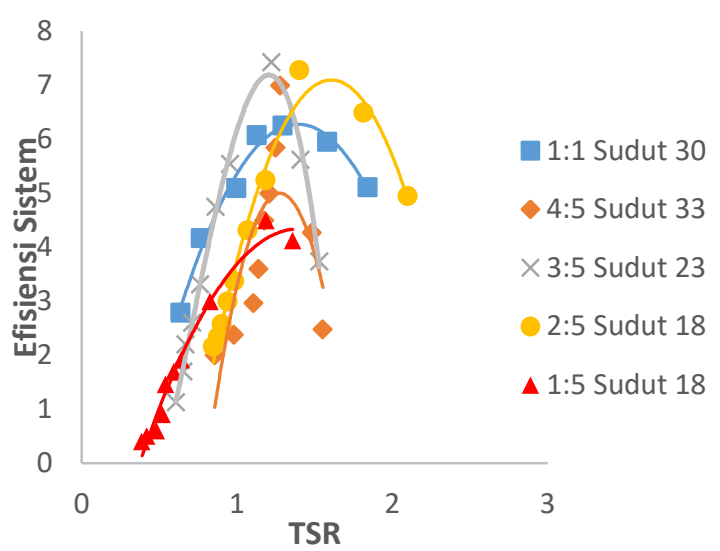

Gambar 4.13 Grafik karakteristik hubungan antara efisiensi sistem $\left(\eta_{\mathrm{s}}\right)$ terbaik terhadap Tip Speed Ratio (TSR) di semua rasio lebar sudu Top dan Bottom pada kecepatan angin bebas $7 \mathrm{~m} / \mathrm{s}$
4.3 Karateristik $\eta_{\mathrm{s}}$ Terbaik Terhadap TSR Turbin Angin Poros Horizontal 9 sudu Flat di Semua Variasi Rasio Lebar Sudu Top dan Bottom pada Kecepatan Angin Bebas $9 \mathrm{~m} / \mathrm{s}$

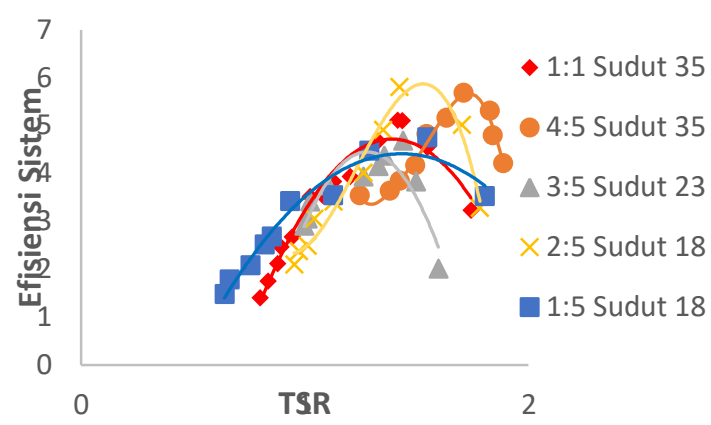

Grafik karakteristik hubungan antara efisiensi sistem $\left(\eta_{\mathrm{s}}\right)$ terbaik terhadap Tip Speed Ratio (TSR) di semua rasio lebar sudu Top dan Bottom pada kecepatan angin bebas $9 \mathrm{~m} / \mathrm{s}$

Gambar $4.1-4.3$ menjelaskan karakteristik hubungan antara $\eta_{\mathrm{s}}$ terhadap TSR pada kecepatan angin bebas $5 \mathrm{~m} / \mathrm{s}, 7 \mathrm{~m} / \mathrm{s}$ dan $9 \mathrm{~m} / \mathrm{s}$ dari kinerja turbin angin poros horizontal 9 sudu flat di semua variasi rasio lebar sudu top dan bottom. Mengacu dari gambar $4.12-4.14$, Nilai $\eta_{\mathrm{s}}$ tertinggi pada kecepatan angin bebas $5 \mathrm{~m} / \mathrm{s}$ yaitu $9,66 \%$ dengan sudut sudu $30^{\circ}$ pada variasi rasio lebar sudu 4:5, Lalu pada kecepatan angin bebas 7 $\mathrm{m} / \mathrm{s}$ nilai $\eta_{\mathrm{s}}$ tertinggi yaitu $7,42 \%$ dengan sudut sudu $23^{\circ}$ pada variasi rasio lebar 3:5. Kecepatan angin bebas $9 \mathrm{~m} / \mathrm{s}$ nilai $\eta_{\mathrm{s}}$ tertinggi yaitu $5,80 \%$ dengan sudut sudu $18^{\circ}$ pada variasi rasio lebar sudu 2:5. 


\section{Penutupan}

\subsection{Kesimpulan}

Berdasarkan tugas akhir rancang bangun yang telah kami buat dapat disimpulkan sebagai berikut :

1. Hasil dari rancang bangun turbin angin yang kita buat memiliki spesifikasi sebagai berikut :

a. Jenis turbin : Turbin angin poros horizontal.

b. Sudu : 9 sudu flat dengan variasi rasio lebar sudu top dan bottom

c. Dimensi sudu : Panjang : $300 \mathrm{~mm}$; lebar sisi bottom : $100 \mathrm{~mm}$; lebar sisi top divariasi dari : $100 \mathrm{~mm}, 80 \mathrm{~mm}, 60$ $\mathrm{mm}, 40 \mathrm{~mm}, 20 \mathrm{~mm}$; tebal : $2 \mathrm{~mm}$.

d. Bahan sudu : Plat Alumunium.

e. Dimensi HUB : Diameter : $160 \mathrm{~mm}$; tebal: $35 \mathrm{~mm}$

f. Bahan HUB : Nilon.

g. Dimensi poros : Diameter :19 mm; panjang : $550 \mathrm{~mm}$.

h. Bahan poros : Besi pejal ST 40.

i. Kerangka : Tinggi rangka atas dan bawah 1,2 $\mathrm{m}$; bahan besi hollow.

j. Sapuan sudu : Diamater Sapuan sudu $85 \mathrm{~cm}$.

k. Generator : Generator DC kapasitas 300 Watt.

2. Efisiensi sistem $\left(\eta_{\mathrm{s}}\right)$ terbesar pada masing-masing variasi rasio lebar sudu adalah sebagai berikut :

a. Pada rasio lebar sudu 1:1 efisiensi sistem $\left(\eta_{\mathrm{s}}\right)$ terbesar adalah 6,24\% yang terdapat dikecepatan $7 \mathrm{~m} / \mathrm{s}$ dan sudut sudu $30^{\circ}$

b. Pada rasio lebar sudu 4:5 efisiensi sistem $\left(\eta_{\mathrm{s}}\right)$ terbesar adalah 9,66\% yang terdapat dikecepatan $5 \mathrm{~m} / \mathrm{s}$ dan sudut sudu $30^{\circ}$

c. Pada rasio lebar sudu 3:5 efisiensi sistem $\left(\eta_{\mathrm{s}}\right)$ terbesar adalah 8,09\% yang terdapat dikecepatan $5 \mathrm{~m} / \mathrm{s}$ dan sudut sudu $20^{\circ}$

d. Pada rasio lebar sudu 2:5 efisiensi sistem $\left(\eta_{\mathrm{s}}\right)$ terbesar adalah 8,43\% yang terdapat dikecepatan $5 \mathrm{~m} / \mathrm{s}$ dan sudut sudu $18^{\circ}$

e. Pada rasio lebar sudu 1:5 efisiensi sistem $\left(\eta_{\mathrm{s}}\right)$ terbesar adalah 4,75\% yang terdapat dikecepatan $9 \mathrm{~m} / \mathrm{s}$ dan sudut sudu $18^{\circ}$

f. Efisiensi Sistem $\left(\eta_{\mathrm{s}}\right)$ terbesar pada semua variasi rasio lebar sudu Top dan Bottom adalah sebesar 9,66\% pada kecepatan $5 \mathrm{~m} / \mathrm{s}$ dan sudut sudu $30^{\circ}$ yang terdapat pada variasi rasio lebar sudu 4:5

\subsection{Saran}

Pengerjaan dan penyelesaian tugas akhir ini tentu tidak lepas dari berbagai macam kekurangan dan kelemahan. Untuk memperbaiki kekurangan tersebut maka saran yang diberikan sebagai berikut :

1. Untuk mendapatkan data yang lebih akurat diperlukan alat ukur yang lebih presisi.

2. Pengujian lima variasi sudu turbin dilakukan dengan perlakuan yang sama agar mendapatkan hasil yang dapat dibandingkan. 


\section{DAFTAR PUSTAKA}

Leysen, E.H.1983.Introduction to Wind Energy. Consultancy Services Wind Energy Developing Countries: Belanda.

Manwell, J.F., J.G. McGowan, A.L. Rogers. 2009. Wind Energy Explained Theory, Designed and Application. Wiley. United State of America

Rizkiyono,Dwi,dkk.2015. Rancang Bangun Turbin Angin Multiblade dengan Generator menggunakan Motor Sepeda Listrik Sebagai Pembangkit Listrik Tenaga Bayu. Tugas Akhir. Semarang: Jurusan Teknik Mesin Polines.

Satriani, Galih Putra dkk.2015. Modifikasi dan Kinerja Turbin Angin Sudu Flat Bingkai Berbasis Trapesium. Tugas Akhir. Semarang: Jurusan Teknik Mesin Polines.

Laila, Mentari. 2010. Rancang Bangun Kincir Angin Model Savonius Termodifikasi Sebagai Sumber Energi Terbarukan. Skripsi. Surakarta: Fakultas Matematika dan Pengetahuan Alam Universitas Sebelas Maret.

Adlie, Taufan Arif, Fazri, \& Zulfan Efendi. (2015). Analisa Biaya Pembuatan Turbin Angin Sumbu Horizontal di Wilayah Pesisir Kota Langsa. Jurutera, 7,3.

Sastrowijoyo, Fajar. "Permasalahan Yang Sering Terjadi Pada Sistem Wind Turbine di Indonesia". 17 Februari 2018. https://konversi.wordpress.com/2008/ 11/06/permasalahan-yang-seringterjadi-pada-sistem-wind-turbine-diindonesia/

Ihsan, Muhammad. "Alternatif Energi Indonesia”. 3 Maret 2018. https://www.penaaksi.com/2011/02/al ternatif-energi-indonesia_25.html

Adzikri, Fikry, Didik Notosudjono, \& Dede Suhendi. Strategi Pengembangan Energi Terbarukan Di Indonesia. Bogor: Progam Studi Teknik Elektro Universitas Pakuan.

Ibrahim, Hasyim. "Design Turbin Angin". 6 Maret 2018.

https://hasyimibrahim.wordpress.com /2009/08/05/design-turbin-angin/

Y., Daryanto. 2007. Kajian Potensi Angin Untuk Pembangkit Listrik Tenaga Bayu. Yogyakarta

Musyafa, Ali. 2012. Sistem Konversi Energi Angin. Surabaya

Huda, Saiful dan Irfan Syarief Arief. 2014. Analisa Bentuk Profile dan Jumlah BladeVertical Axis Wind Turbine terhadap Putaran Rotor untuk Menghasilkan Energi Listrik. Surabaya : Jurusan Teknik Sistem Perkapalan Intitut Teknologi Sepuluh November. 